\title{
Aperfeiçoamento do Programa de Monitoria do Instituto Federal Goiano - CAMPUS CERES POR MEIO DE HistóRIAS EM QUADRINHOS
}

\author{
IMPROVEMENT OF FEDERAL INSTITUTE GOIANO - CAMPUS CERES \\ MONITORING PROGRAM THROUGH COMICS
}

DOI: http://dx.doi.org/10.23926/RPD.2526-2149.2020.v5.n1.p469-488.id500

\author{
Clécia Messias de \\ Sousa \\ Mestra em Educação \\ Profissional e Tecnológica \\ (IF Goiano/Campus \\ Morrinhos) \\ clecia.sousa@ifgoiano.edu.b \\ r
}

\section{José Carlos Moreira de Souza}

Doutor em Educação (UFG) rofessor no Instituto Federal Goiano (IF Goiano) jose.moreira@ifgoiano.edu.b $\underline{r}$

\begin{abstract}
Resumo: O objetivo do artigo é apresentar uma História em Quadrinhos (HQ) como ferramenta educacional de aperfeiçoamento do Programa de Monitoria do Instituto Federal Goiano - Campus Ceres. A monitoria como ferramenta pedagógica, na vida acadêmica dos alunos tem sido estudada e discutida como formação unitária, tornando-os sujeitos ativos e colaborativos no processo de ensino-aprendizagem. O uso da HQ dinamiza a apresentação de temas diversos e se torna eficaz ao focar no público-alvo do Programa de Monitoria. A pesquisa foi realizada entre os anos de 2018 e 2019, a partir de uma análise quantitativa e qualitativa dos dados obtidos por meio da aplicação de questionários e entrevistas aos alunos, professores e equipe pedagógica do Campus Ceres. Os resultados indicaram a relevância do Programa de Monitoria na dinamização do processo de ensino-aprendizagem e, consequentemente, sua contribuição para a permanência e o êxito escolar. Assim, elaborou-se a HQ intitulada "A Importância da Monitoria" visando chamar a atenção de professores e alunos para a participação no programa, destacando as possibilidades de desenvolvimento pessoal das partes envolvidas e atentando para os problemas que se apresentam no percurso. Esta HQ mostrou-se uma importante ferramenta pedagógica para a melhoria das monitorias do IF Goiano - Campus Ceres.
\end{abstract}

Palavras-chave: Monitoria; Produto educacional; História em quadrinhos; Ensino-aprendizagem.

\begin{abstract}
The objective of the article is to present a Comic Book (HQ) as an educational tool to improve the Monitoring Program of Federal Institute Goiano - Campus Ceres. The monitoring as a educational tool in the students's academic life, has been studied and discussed as unitary formation, making them active and colaborative subjects in the teachinglearning process. The use of HQ dynamize the presentation of many diversificate themes and become effective by focusing on the target audience of the Monitoring Program. The research was carried out between the years 2018 and 2109, based on a quantitative and qualitative analysis of the data obtained through the application of questionnaries and interviews to students, teachers and pedagogic staff of Campus Ceres. The results indicated the relevance of the Monitoring Program by the dynamization of the teaching-learning process and, consenquently, its contribution to the permanence and school success. Thus, the HQ entitled "The Importance of Monitoring" was elaborated seeking to call atention of teachers and students to participate in the monitoring program, highlighting the possibilities of personal development of students and paying attention to the problems that appearing through the way. This HQ showed to be an important pedagogic tool to the improvement of monitoring program of IF Goiano - Campus Ceres.
\end{abstract}

Keywords: Monitoring; Educational product; Comics; Learning-teaching process. 


\section{INTRODUÇÃO}

Este artigo é um recorte da dissertação de mestrado intitulada: A Eficiência da Monitoria nos Cursos Técnicos Integrados ao Ensino Médio do Instituto Federal Goiano - Campus Ceres: o Processo de Ensino-Aprendizagem, Permanência e Êxito Escolar. A pesquisa teve como objetivo avaliar a eficiência do Programa de Monitoria, compreendendo o alcance dessa prática, que integra a proposta político-pedagógica da instituição, no processo de ensino.

O propósito do artigo é apresentar o Produto Educacional, em formato de História em Quadrinhos (HQ), elaborado a partir da pesquisa supracitada. Tal produto é exigência do Programa de Mestrado Profissional em Educação Profissional e Tecnológica (ProfEPT). Tratase de um Mestrado Profissional da área de Ensino, cuja intenção com sua elaboração é articular a teoria com a pesquisa, implementando-a como parte integrante do percurso formativo do profissional.

Inicialmente, realizou-se um levantamento teórico acerca da educação profissional integrada ao ensino médio como formação unitária e sobre a monitoria no processo de ensinoaprendizagem como ferramenta de apoio pedagógico. Apresentou-se, ainda, os procedimentos metodológicos observados na elaboração da $\mathrm{HQ}$, alguns resultados da pesquisa utilizados no desenvolvimento da história e por último, como o produto educacional foi avaliado e validado durante a pesquisa.

Os Produtos Educacionais são ferramentas que contribuem com as práticas pedagógicas e que devem ser divulgados e disponibilizados após a sua elaboração, tendo em vista que um de seus objetivos é que seu uso seja democratizado, "visando à melhoria do ensino na área específica" (MOREIRA, 2004, p. 134). Para Sousa (2015, p. 05), o Produto Educacional é o resultado de um processo reflexivo e contextualizado.

Tal produto não é mera transposição didática de uma escola para a outra. Muito menos um material didático pronto para ser manipulado por professores e estudantes. Pelo contrário, é vivo, contem fluência, movimento e nunca está pronto e acabado porque representa a dinâmica das aulas [...] vivenciada pelos estudantes

Assim, as HQs caracterizam-se como Produtos Educacionais, pois têm a intenção de influenciar a inserção de diferentes práticas que podem trazer contribuições positivas no processo de ensino-aprendizagem. De acordo Vergueiro (2004, p. 26), no caso dos quadrinhos, "pode-se dizer que o único limite para seu bom aproveitamento [...] é a criatividade do professor e sua capacidade de bem utilizá-los para atingir seus objetivos de ensino". 


\title{
2 REFERENCIAL TEÓRICO
}

\subsection{A EDUCAÇÃo PROFISSIONAL INTEGRAda AO ENSINO MÉdIO COMO FORMAÇÃO UNITÁRIA}

Um dos principais objetivos da Educação Profissional e Tecnológica (EPT) é alcançar a formação integral e unitária, para tanto, diversos autores como Frigotto (2012), Ramos (2007, 2012) e Ciavatta (2012), amparados pela proposta educacional de Gramsci, voltada para a emancipação da classe trabalhadora, sugerem superação entre trabalho manual e trabalho intelectual, o que significaria enfocar o trabalho como princípio educativo, que na concepção de Gramsci (1981, p. 144 e ss. apud CIAVATTA, 2012, p. 84), "significa incorporar a dimensão intelectual ao trabalho produtivo, de formar trabalhadores capazes de atuar como dirigentes e cidadãos".

\begin{abstract}
A concepção da escola unitária expressa o princípio da educação como direito de todos. Uma educação de qualidade que possibilite a apropriação dos conhecimentos construídos até então pela humanidade, o acesso à cultura, etc. Não uma educação só para o trabalho manual e para os segmentos menos favorecidos, ao lado de uma educação de qualidade e intelectual para o outro grupo. (RAMOS, 2007, p. 02).
\end{abstract}

Para Frigotto, Ciavatta e Ramos (2012, p. 45), o ensino técnico integrado ao ensino médio é uma necessidade histórica e social, para a efetivação da educação tecnológica entre os filhos da classe dos trabalhadores. Nesse sentido, visando à formação integral do ser humano, os autores apontam essa possibilidade de integração entre formação geral e técnica no ensino médio como "condição necessária para a travessia em direção ao ensino médio politécnico e à superação da dualidade educacional pela superação da dualidade de classes".

Nessa perspectiva, os Institutos Federais de Educação, Ciência e Tecnologia (IFs) com o objetivo de minimizar a dualidade estrutural existente na educação brasileira e articular teoria e prática, consolidando a tríade ensino, pesquisa e extensão, recebem alunos de diversas origens e classes sociais, com intuito de oferecer essa formação integrada entre todas as dimensões da vida: cultura, ciência e trabalho, ou seja, uma formação para o exercício da vida produtiva. Pacheco (2011) afirma que o fazer pedagógico desses institutos tenta romper com um formato consagrado, fragmentado e secular de lidar com o conhecimento. É nesse sentido, que o IF Goiano coloca a indissociabilidade entre ensino, pesquisa e extensão em seu Plano de Desenvolvimento Institucional (PDI) 2019 a 2023.

A relação do conhecimento com o mundo do trabalho representa condição indispensável para um ensino de qualidade, no qual os conteúdos trabalhados sejam contextualizados e tratados de forma integrada, levando a uma constante reflexão e intervenção na realidade atual. Essa relação oportuniza o rompimento da dicotomia 
entre a teoria e a prática e entre a formação técnica e a formação humana, objetivando uma formação integrada e integral. Dessa forma, a prática educativa deve promover o desenvolvimento do senso crítico do estudante em relação ao mundo e ao pleno exercício de sua cidadania, capacitando-o para as inovações tecnológicas. Essas premissas devem estar pautadas nos princípios da igualdade, solidariedade, equidade e sustentabilidade, que estão em consonância com os objetivos de melhorar as condições de vida da população, de criar mecanismos para uma melhor redistribuição de renda e de, consequentemente, primar por uma maior justiça social. Assim, a indissociabilidade entre ensino, pesquisa e extensão deve promover a articulação das diferentes áreas de conhecimento e a inovação científica, tecnológica, social, artística e cultural. (BRASIL, 2018, p. 64).

Os Institutos Federais de Educação têm um público-alvo diverso, e alguns deles recebem alunos de comunidades indígenas, quilombos e assentamentos rurais, bem como de escolas públicas com ensino de baixa qualidade, tendo uma base de conhecimentos frágil. Desse modo, possuem diferenças de ordem social, cultural, econômica, política, religiosa entre outras, mas principalmente relacionadas às dificuldades no processo de ensino-aprendizagem, tendo em vista sua formação no ensino fundamental.

Assim, é necessário questionar se esse objetivo proposto pelos Institutos Federais tem sido alcançado; como ocorre essa integração; se realmente há perspectiva de superação dessa dualidade; pois, como as diferenças entre os alunos que são recebidos por essas instituições são grandes, é imprescindível que as mesmas sejam reconhecidas e trabalhadas com intuito de minimizá-las. Nesse sentido, Kuenzer (2002) afirma que é necessário destacar o papel da escola pública na construção de uma proposta pedagógica que proporcione situações de aprendizagem variadas e significativas aos seus alunos, na maior parte pauperizados economicamente, e, consequentemente, empobrecidos cultural e socialmente.

É essa nova compreensão que permitirá superar a profissionalização estreita, restrita à apropriação de modos de fazer para uma parcela da população condenada a priori à pobreza cultural, tida como irremediável em face da pobreza econômica, para a qual em princípio, qualquer esforço pedagógico será inútil. (KUENZER, 2002. p. 43).

Para tanto, é de suma importância que a instituição ofereça ferramentas pedagógicas de apoio a esses alunos, para que os mesmos tenham a oportunidade de recuperar os conteúdos em defasagem e acompanhar o desenvolvimento acadêmico alcançado pelos demais colegas de curso, bem como para ajudar os alunos com perfil desinteressado, tentando, dessa forma, aumentar o índice de permanência e êxito escolar dos mesmos.

Nesse sentido, uma das possibilidades como ferramenta de apoio pedagógico extraclasse é a monitoria. Ela deve ser ministrada pelos alunos que estão em séries mais avançadas e têm, consequentemente, mais conhecimentos em determinadas disciplinas, além de possuírem maior facilidade de aprendizagem e capacidade de auxílio na construção do conhecimento. 


\subsection{A MONITORIA NO PROCESSO DE ENSINO-APRENDIZAGEM COMO FERRAMENTA DE} APOIO PEDAGÓGICO

A monitoria está presente em grande parte dos Institutos Federais do país, sendo trabalhada paralelamente ao andamento dos cursos em sala de aula. Trata-se de uma ferramenta didático-pedagógica relevante na formação do cidadão apto para viver e produzir em sociedade, tendo em vista que a EPT não pode ser vista como simples qualificação de mão de obra para o mercado de trabalho, mas deve superar esse conceito e formar cidadãos emancipados, críticos, reflexivos, atuantes e transformadores da realidade social na qual estão inseridos e atuar no mundo do trabalho. Dessa forma, a realização de estudos relacionados à prática da monitoria é necessária para que alunos e professores compreendam sua importância e benefícios, bem como para analisar o que pode ser passível de melhora no processo de ensino-aprendizagem.

Para Haag et al. (2008), a monitoria é uma atividade de apoio pedagógico ofertada aos alunos com interesse em aprofundar conteúdos, bem como solucionar dificuldades em relação à matéria trabalhada em sala de aula. Desse modo, a monitoria pode ser compreendida como oportunidade para os participantes aumentarem seus conhecimentos, sanarem dúvidas em atividades mais complicadas, revisarem conteúdos e principalmente estabelecerem relações importantes de mediação.

Nesse sentido, Frison e Moraes (2010), entendem a monitoria como uma estratégia de apoio ao ensino, na qual os alunos mais adiantados nos estudos ajudam nos processos de apropriação do conhecimento de seus colegas. Sendo que os monitores atuam como mediadores da aprendizagem com os alunos que apresentam dificuldades na compreensão dos conteúdos do currículo proposto.

Nas palavras de Jesus et al. (2012), a monitoria traz benefícios para professores, alunos monitores e não monitores.

\footnotetext{
Um aluno-monitor comprometido e consciente da função a ser desempenhada tende mostrar evolução em diversos aspectos, como por exemplo: aprofundamento no conteúdo da disciplina, melhora na linguagem e na comunicação com os pares, desenvolvimento de senso de responsabilidade, comprometimento, consciência coletiva, proatividade, dentre outros. Os alunos que podem usufruir da monitoria aprendem de forma mais interativa e dinâmica, desenvolvem o controle de seu próprio processo de aprendizagem [...], além de encontrarem um ambiente motivador para a sua aprendizagem, já que o ensino ocorre entre pares, [...]. O professor à frente de um programa de monitoria se beneficia na medida em que exerce um papel de liderança no projeto, coordenando as atividades propostas e adquirindo experiência a partir desta oportunidade, [...]. (JESUS et al., 2012, p. 64-65).
}

Nesse contexto, a monitoria caracteriza-se como um espaço que estabelece relações sociais em que são construídos vínculos aluno-aluno e aluno-professor, que podem interferir 
diretamente no processo de ensino-aprendizagem. Assim sendo, com o intuito de minimizar a defasagem no processo de ensino-aprendizagem e aumentar a permanência e o êxito escolar, as instituições de ensino tem procurado estabelecer medidas didático-pedagógicas, no sentido de mediar a apropriação de conhecimentos, de modo que o aluno seja ativo, crítico e participante desse processo.

Em vista disso, a monitoria, que coloca o aluno em uma posição participativa, colaborativa e atuante na relação ensino-aprendizagem, apresenta-se como uma possibilidade para tentar minimizar essa defasagem. Investigar como ocorre essa intervenção no processo de aprendizagem por meio do Programa de Monitoria é de suma importância, tendo em vista que esse programa pode influenciar no sucesso ou fracasso escolar do discente.

Nessa perspectiva, ressalta-se a experiência do IF Goiano - Campus Ceres, que oferece o Programa de Monitoria todos os anos, para os cursos técnicos integrados ao ensino médio e também para os cursos de graduação. O programa é dividido em duas categorias: remunerada e voluntária, e em ambas modalidades têm sido ofertadas vagas para monitores nas mais diversas disciplinas, principalmente naquelas em que existem maiores índices registrados de evasão e retenção em anos anteriores.

\title{
3 Metodologia
}

Para o presente artigo foi utilizada a pesquisa bibliográfica, de natureza quantitativa e qualitativa, na modalidade exploratória e descritiva. De acordo com Gil (2010),

\begin{abstract}
A pesquisa bibliográfica é elaborada com base em material já publicado. Tradicionalmente, esta modalidade de pesquisa inclui material impresso, como livros, revistas, jornais, teses, dissertações e anais de eventos científicos. Todavia, em virtude da disseminação de novos formatos de informação, estas pesquisas passaram a incluir outros tipos de fontes, como discos, fitas magnéticas, CDs, bem como o material disponibilizado pela Internet. (GIL, 2010, p. 29).
\end{abstract}

Visando o levantamento de dados referentes ao Programa de Monitoria desenvolvido no IF Goiano - Campus Ceres para elaborar o roteiro da HQ, utilizou-se dos resultados do trabalho intitulado: “A Eficiência da Monitoria nos Cursos Técnicos Integrados ao Ensino Médio do Instituto Federal Goiano - Campus Ceres: o Processo de Ensino-Aprendizagem, Permanência e Êxito Escolar". Este foi desenvolvido no âmbito do ProfEPT, de outubro de 2018 a maio de 2019, no qual foram obtidas respostas de 62 sujeitos, sendo 31 alunos não monitores, 17 alunos monitores, 10 professores orientadores e 04 membros da equipe pedagógica, a questionários e entrevistas com questões fechadas e abertas. Buscou-se identificar dentre outros aspectos, os avanços percebidos em relação à aprendizagem, às 
dificuldades encontradas no desenvolvimento da prática das atividades de monitoria e a orientação recebida pelos monitores por parte dos professores orientadores.

Por se tratar de pesquisa envolvendo seres humanos, o estudo foi submetido, apreciado e aprovado pelo Comitê de Ética em Pesquisa (CEP) do Instituto Federal Goiano, conforme preconizado pelo Conselho Nacional de Saúde (CNS) por meio da Resolução nº 466, de 12 de dezembro de 2012 (CNS, 2012) e da Resolução nº 510, de 07 de abril de 2016 (CNS, 2016). Diante disso, ressalva-se que a pesquisa atendeu às exigências éticas e científicas, e, por meio do Termo de Consentimento Livre e Esclarecido (TCLE) e do Termo de Assentimento Livre e Esclarecido (TCAE), os participantes tiveram garantidos o anonimato e a participação voluntária. A pesquisa não resultou em riscos ou desconforto algum aos participantes. Faz-se importante mencionar que a participação dos mesmos no estudo acarreta como benefício o aumento do conhecimento científico relacionado a essa temática para a área do Ensino.

\section{Utilização de resultados da pesquisa na elaboração da História em QUADRINHOS}

Analisando as respostas obtidas, foi possível fazer algumas inferências acerca da prática da monitoria. Na Figura 1 pode-se visualizar os principais motivos que levaram os alunos a procurarem o Programa de Monitoria (pergunta feita para alunos não monitores).

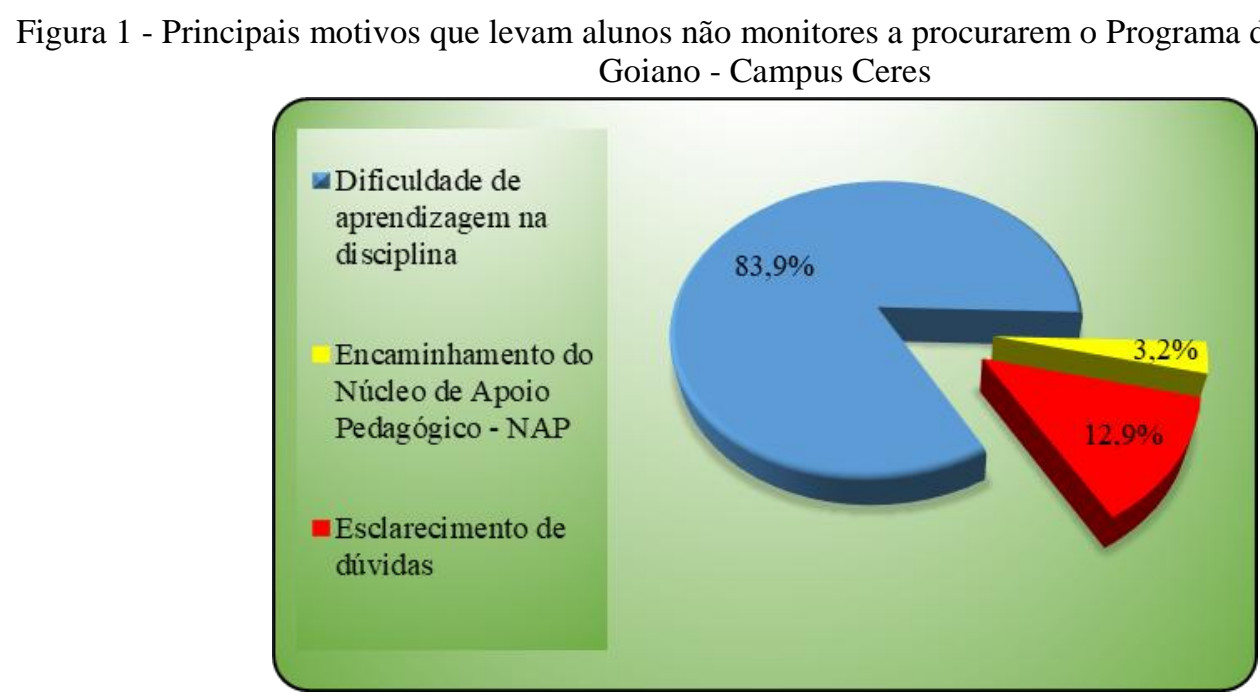

Fonte: Tabulação de dados realizada pela autora.

Os respondentes, em sua maioria, 83,9\%, afirmaram que o principal motivo foi a "dificuldade de aprendizagem na disciplina", 12,9\% deles afirmaram ser o "esclarecimento de dúvidas" e 3,2\% responderam que foram "encaminhados pelo Núcleo de Apoio Pedagógico (NAP). 
Quando perguntados se achavam que a monitoria contribui para a aprendizagem dos alunos, todos os alunos não monitores responderam que "Sim", justificando sua resposta, conforme as falas a seguir: "Sim, pois na monitoria pode focar onde se tem mais dificuldade e a maneira de que um aluno explica para o outro pode facilitar o aprendizado"; "Sim, pois através da monitoria as dúvidas nas disciplinas que não foram esclarecidas em sala de aula serão retiradas por alunos que podem estabelecer uma conversa que haja mais esclarecimento para os alunos que possuírem dificuldades"; "Sim, pois ajuda o aluno a relembrar aquela matéria que teve dificuldade e, explicar de outra forma até sendo uma forma mais fácil."; "Sim, pois é uma forma prática de ajudar os alunos, às vezes o aluno compreende melhor a linguagem do monitor do que do professor, além de ser uma forma de esclarecer dúvidas que surgem no decorrer dos estudos, mais fácil que conversar com o professor"; "Sim, acho a monitoria super importante pois além de dar uma reforçada no que o professor passa, tira alguma dúvida que o aluno(a) tinha na sala de aula e etc." (ALUNO 01; ALUNO 06; ALUNO 18; ALUNO 25 e ALUNO 29).

Os alunos monitores também responderam que "Sim" a esta pergunta, justificando suas respostas da seguinte forma: "Vários possuíam dificuldades em aplicar regras básicas de raciocínio lógico matemático à disciplina"; "Ficou bem notável o desenvolvimento dos alunos que participaram da monitoria durante o semestre"; "Pois no instante que um aluno se dirige à alguma monitoria, ela se esforça e nesse momento, esse esforço promove um aprendizado mais real e concreto"; "Pois através da monitoria os alunos podem esclarecer as dúvidas que na maioria das vezes não são esclarecidas em sala de aula. Além disso, os estudantes têm a oportunidade de obter maior conhecimento em temas específicos"; "Visto que a maioria dos alunos que frequentavam a monitoria tiveram bons resultados nas provas da disciplina monitorada" (MONITOR 02, MONITOR 07, MONITOR 09, MONITOR 11 e MONITOR 14).

Ao analisar as monitorias/disciplinas que os alunos frequentaram no primeiro e segundo semestre de 2018, verifica-se que a área de exatas teve maior procura, sendo que as disciplinas de Matemática, Física e Química do primeiro ano, entre as disciplinas do núcleo comum, foram mais procuradas, o que evidencia a base frágil de conhecimentos adquirida no ensino fundamental (Figura 2). 
Figura 2 - Percentual de frequência dos alunos do IF Goiano - Campus Ceres nas Monitorias/Disciplinas ofertadas no primeiro semestre de 2018

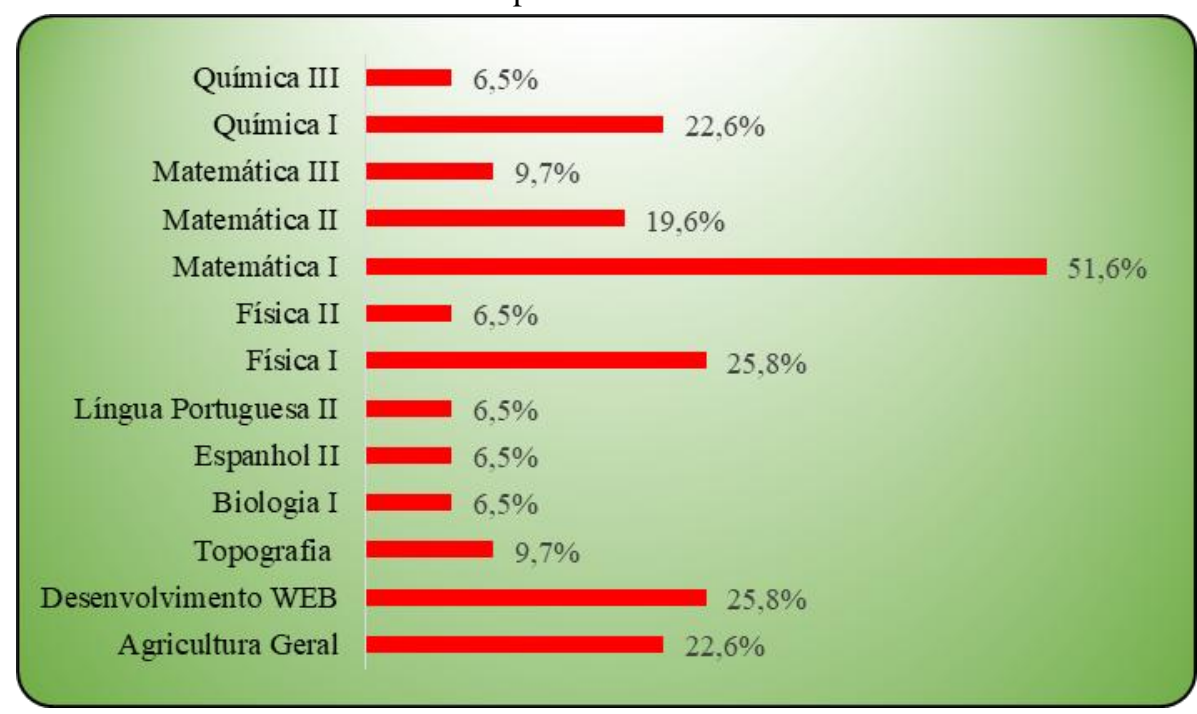

Notas: Estão relacionadas todas as disciplinas/monitorias do núcleo comum. Das disciplinas/monitorias da parte específica, estão relacionadas somente as disciplinas críticas estudadas na pesquisa.

Fonte: Tabulação de dados realizada pela autora.

A partir das respostas obtidas, nota-se que a percepção dos alunos em relação à monitoria é positiva e que realmente ela influencia, de forma favorável, no processo de ensinoaprendizagem. Ela os ajuda a minimizar a defasagem na aprendizagem de conteúdos existentes entre os mesmos devido às diferenças em suas origens locais, sociais, econômicas e culturais, proporcionando-os um mínimo de chances perante a vida e o mundo do trabalho, tendo em vista que, conforme compreensão e formulação conceitual desenvolvida por Anastasiou e Alves (2006), a monitoria desencadeia um processo de construção de autonomia, controle e consciência para o sujeito e para o grupo.

De acordo com Cunha Júnior (2009, p. 24),

[...] na medida em que tem apoio dos monitores, o aluno não monitor diminui o nível de dependência e passa a realizar atividades por si só. É preciso salientar que os monitores necessitam ser preparados para o trabalho a ser desenvolvido. Ser monitor é um processo de aprendizagem e desenvolvimento bastante complexo.

Cavalheiro (2008) afirma que proporcionar ao aluno a oportunidade de trabalhar e interagir com seus colegas é um desafio. Por meio da cooperação, no cotidiano, pode-se criar um ambiente de ajuda mútua, respeito pelas diferenças e responsabilidade compartilhada podendo desenvolver habilidades sociais.

Os estudantes monitores tendem a se colocar no lugar dos outros e a resolver problemas que necessitam de cooperação para serem solucionados, além de passar a gostar mais de ir à escola e aprender, utilizando e aprimorando suas habilidades de comunicação e raciocínio. As atividades de monitoria se tornam estratégias 
pedagógicas apropriadas para fortalecer o companheirismo entre os colegas e a desenvolver a comunicação, o que se torna comum a todos com a troca de ideias entre os alunos. (CAVALHEIRO, 2008, p. 47).

Os dados da pesquisa também revelaram informações acerca da orientação realizada pelos professores e obteve-se os seguintes resultados: 47,05\% dos professores orientadores "sempre" programam as atividades de monitoria junto com os monitores, 47,05\% programam essas atividades "apenas em alguns momentos" e 5,9\% "nunca" programam.

Outro fator pesquisado entre alunos monitores e que deve ser considerado, pois tem implicações no desempenho de suas atividades, se refere a qual o principal motivo que os levou a se inscreverem no Programa de Monitoria, cujas respostas seguem apresentadas na Figura 3.

Figura 3 - Principais motivos para os monitores se inscreverem no Programa de Monitoria do IF Goiano Campus Ceres

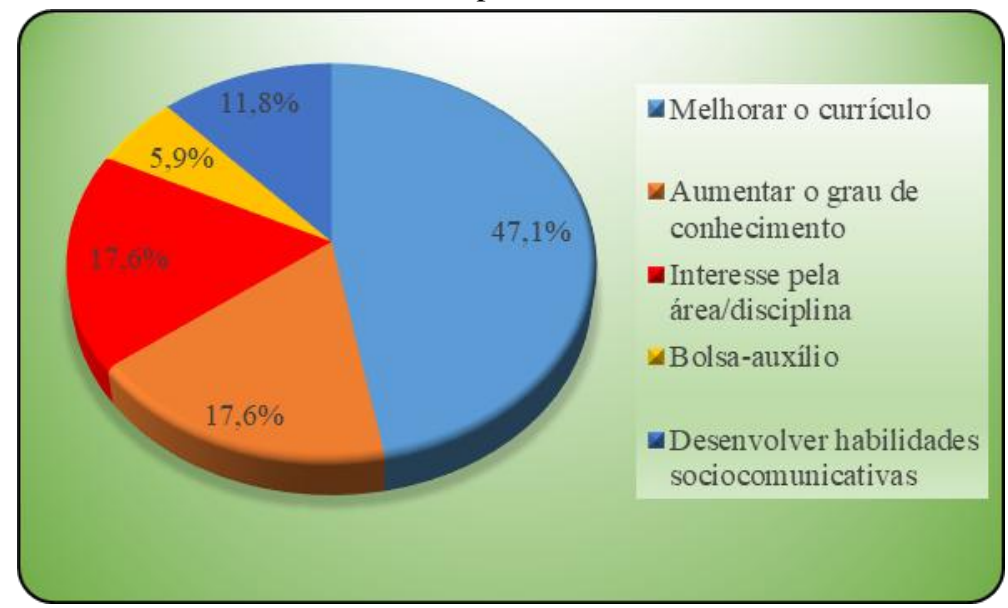

Fonte: Tabulação de dados pela autora.

Conforme se infere dos dados analisados, pondera-se, aqui, que a maioria dos monitores, o equivalente a 47,1\%, se inscreveu no Programa de Monitoria com a intenção de melhorar o currículo, enquanto $17,6 \%$ se inscreveram com o objetivo de aumentar o grau de conhecimento e por interesse pela área/disciplina, 11,8\% para desenvolver habilidades sociocomunicativas e apenas $5,9 \%$ por interesse na bolsa-auxílio. Nesse mesmo diapasão, os alunos foram solicitados a avaliar os eventuais impactos que a experiência como monitor possa exercer em sua carreira/atividade profissional. As respostas obtidas estão expostas na Figura 4. 
Figura 4 - Eventuais impactos na carreira/atividade profissional ocasionados pela atividade de monitoria do IF Goiano - Campus Ceres

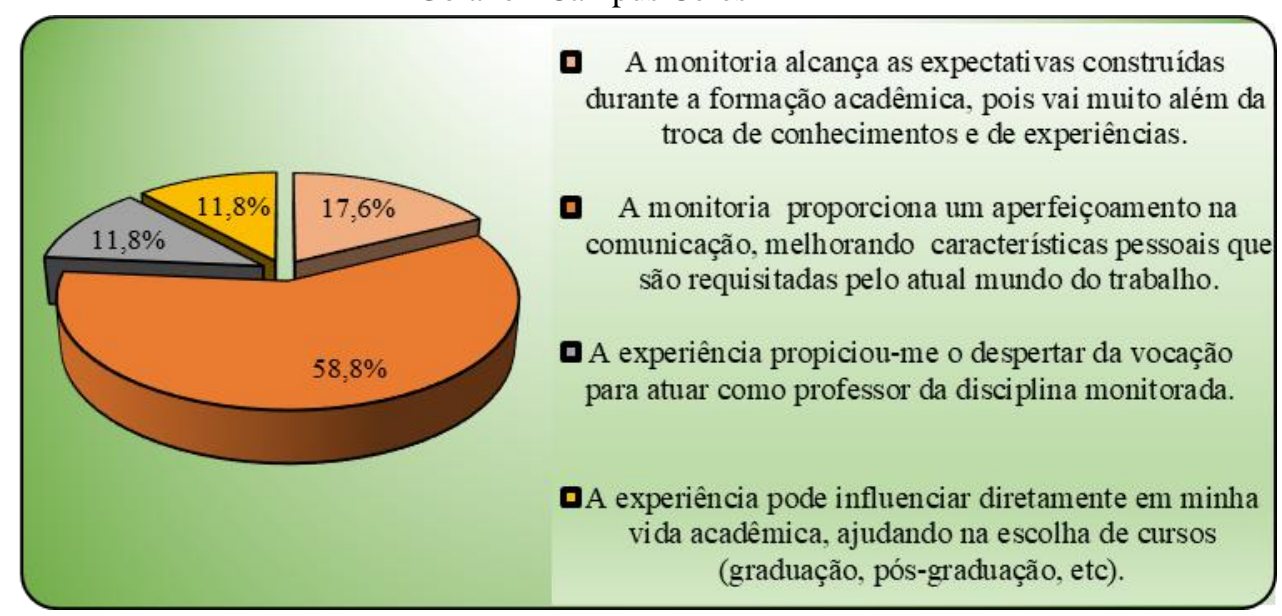

Fonte: Tabulação de dados realizada pela autora.

De acordo com as respostas obtidas, fica claro que para a maioria, 58,8\% dos monitores, a prática da monitoria proporciona uma melhora nas características pessoais, principalmente na comunicação, requisitadas pelo mundo do trabalho. Para $17,6 \%$ vai muito além da troca de conhecimentos e de experiências e $11,8 \%$ consideraram que a experiência despertou a vocação para atuar como professor e que também pode influenciar na escolha de cursos de graduação e pós-graduação, entre outros. Esses dados evidenciam que, por meio dessa ferramenta pedagógica, tanto o desejo para ser docente, devido às práticas utilizadas na monitoria, quanto para realizar o estágio obrigatório e seguir carreira profissional em áreas correlatas, em razão do aprofundamento dos estudos nas disciplinas específicas dos cursos técnicos, podem ser potencializadas no Programa de Monitoria.

Analisa-se, assim, a monitoria como uma forma de tentar minimizar a dualidade existente na educação profissional, pois, de acordo com Kuenzer (2002), o ensino médio é mediação necessária para o mundo do trabalho, por meio da síntese entre ciência trabalho e cultura, não sendo possível a formação profissional sem uma sólida base de educação geral.

Nesse sentido, faz-se necessária a superação da ruptura que existe historicamente entre uma escola que ensine a pensar e a apropriar-se do conhecimento produzido e acumulado histórica e socialmente, e uma escola que ensine a fazer, por meio da memorização de procedimentos e desenvolvimento de habilidades. Assim, com os dados da pesquisa, iniciou-se o desenvolvimento do Produto Educacional, com a intenção de auxiliar o Programa de Monitoria a melhorar sua atuação no processo de construção colaborativa de conhecimento. 


\subsection{O processo de Criação da História em Quadrinhos como Produto} EDUCACIONAL

De acordo com a Coordenação de Aperfeiçoamento de Pessoal de Nível Superior (CAPES), a ênfase dos cursos de Mestrados Profissionais da área de Ensino deve ser na aplicação do conhecimento e no desenvolvimento dos produtos educacionais. O Documento de Área - Ensino diz que,

O Mestrado Profissional destaca a produção técnica/tecnológica na área de Ensino, entendida como produtos ou processos educacionais que possam ser utilizados por professores e outros profissionais envolvidos com o ensino em espaços formais e não formais. (BRASIL, 2013, p. 27).

O mesmo documento enquadra como "material textual (manuais, guias, textos de apoio, artigos em revistas técnicas ou de divulgação, livros didáticos e paradidáticos, história em quadrinhos e similares).” (BRASIL, 2013, p. 27). Com a intenção de divulgar resultados da pesquisa, explicar como a monitoria funciona, seus objetivos, contribuir para o processo de ensino-aprendizagem, ampliar a participação de professores e alunos no programa, tentando aumentar a permanência e o êxito escolar, o Produto Educacional desenvolvido foi uma HQ, classificado pela CAPES, como material textual.

A opção pelo desenvolvimento no formato em HQ se deve ao fato de que o mesmo possui uma linguagem mais próxima do público-alvo, que em sua maioria são os alunos dos cursos técnicos integrados ao ensino médio. Concorda-se com Mendonça (2007), quando afirma que o reconhecimento e a utilização dos quadrinhos como ferramenta pedagógica parece impor-se como necessidade, numa época em que a imagem e a palavra, cada vez mais, associam-se para a produção de sentido nos diversos contextos comunicativos. No mesmo sentido Kaplúm (2003, p. 54), afirma que é "preciso animar-se a romper moldes para que a mensagem educativa não seja, uma vez mais, equivalente a um sermão impresso, ou a uma chatice audiovisual. Tudo isso sempre girando em torno ao nosso eixo pedagógico".

Ainda de acordo com Kaplúm (2003), o processo para a criação de um material educacional se divide em três fases: a criação, produto, e o uso posterior. O material precisa ter importância e acrescentar algo para o público que irá atingir, caso contrário, será deixado de lado. Nesse sentido, os eixos elencados por ele auxiliam na produção de um material educativo:

- Eixo Conceitual: é preciso conhecer os conceitos, ler autores importantes sobre o tema e escolher as ideias centrais que serão abordadas pelo material.

- Eixo Pedagógico: expressa o caminho que convidamos o sujeito a percorrer, quem ele é, e onde está antes de começar. 
- Eixo Comunicacional: está relacionado ao formato, diagramação e linguagem utilizada na confecção do material educativo.

Para o desenvolvimento do Produto Educacional foram observados os aspectos elencados por Kaplúm (2003), e com base nas respostas dos sujeitos pesquisados foi elaborado previamente um roteiro para a criação da HQ com o intuito de chamar a atenção de professores e alunos para as possibilidades e também para os problemas que se apresentam no Programa de Monitoria do IF Goiano - Campus Ceres.

Com relação a cenário e caracterização de personagens em HQs, Carvalho (2006) ressalta que,

\begin{abstract}
Uma boa HQ traz em suas páginas personagens muito bem elaborados. Além de os textos exigirem concisão, os personagens precisam ser representados de maneira adequada ao que devem representar (tanto nas vestimentas quanto nas características físicas), falar de forma convincente. Por esse motivo, a oralidade é (e precisa ser) bastante respeitada para que um personagem seja convincente [...]. (CARVALHO, 2006, p. 91).
\end{abstract}

Levando esses fatores em consideração, na elaboração do produto, atentou-se para diversidade sociocultural e racial dos alunos da instituição. Assim, foi criado um ambiente familiar para os alunos e utilizando-se de uma linguagem próxima a empregada no dia a dia por eles, de modo que se identificassem na história, despertando, desse modo, o interesse pela leitura. Segundo Oliveira et al. (2007), personagens conhecidos do público inspiram sentimentos como confiança e aceitação de ideias; são, portanto, uma via hábil para a construção de materiais educativos, posto que também geram no público a sensação de identificação e transferência de responsabilidades, afinal, os artifícios visuais são poderosos veículos de comunicação sobre valores sociais e morais, compondo um código socialmente aceito e compreendido.

De acordo com Rebolho, Casarotto e João (2009, p. 49) “A facilidade com que a história em quadrinhos comunica conhecimentos científicos está relacionada ao fato de que ela transmite informações de forma atrativa, divertida e facilita a memorização de conceitos". Dessa forma, ressalta-se que de maneira mais lúdica os professores, alunos, bem como a equipe pedagógica da instituição, podem ter uma percepção melhor de como o Programa de Monitoria funciona e também apresentarem sugestões para que o mesmo possa ser mais eficiente com a finalidade de obter sucesso no processo de ensino-aprendizagem e aumentar a permanência e o êxito escolar.

Segue abaixo tela inicial, tela explicativa e uma das telas com falas dos personagens, todas constantes na HQ produzida. 
Figura 5 - Tela inicial da História em Quadrinhos

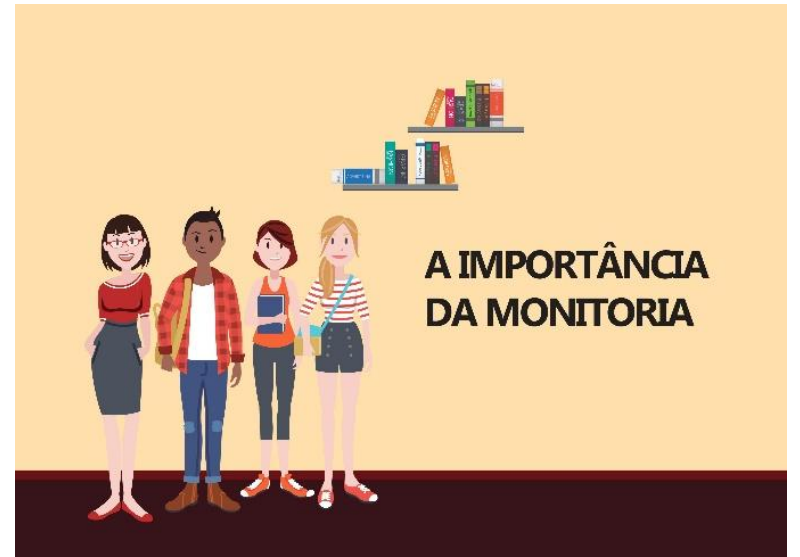

Fonte: Produto Educacional desenvolvido pela própria autora.

Figura 6 - Tela explicativa da História em Quadrinhos

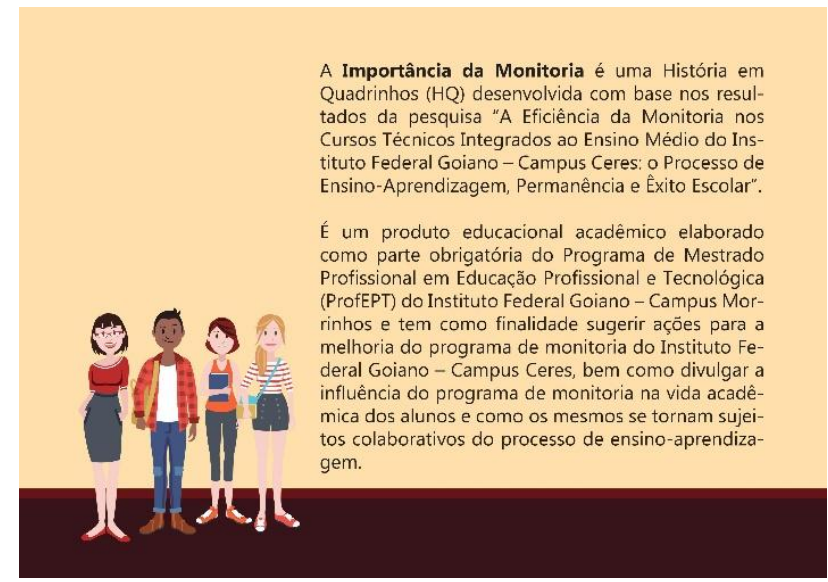

Fonte: Produto Educacional desenvolvido pela própria autora.

Figura 7 - Tela com falas dos personagens da História em Quadrinhos

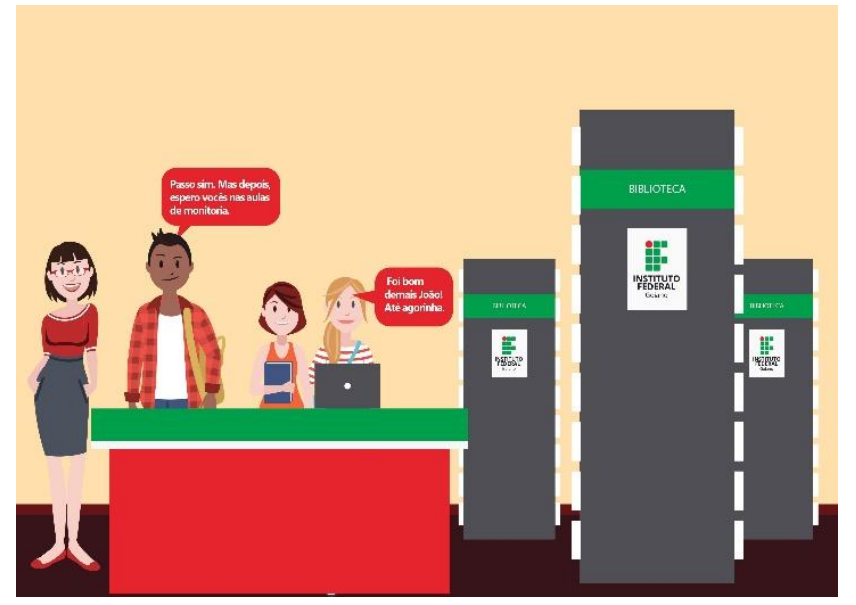

Fonte: Produto Educacional desenvolvido pela própria autora.

Após a elaboração do roteiro e a criação da HQ, observou-se o estudo de Amiel (2014), em relação ao último passo, após criar um Recurso Educacional, qual seja, compartilhar. Para esse autor é preciso criar, relacionar e compartilhar para então completar o círculo virtuoso da criação. "O último passo, compartilhar, é o menos comum e mais trabalhoso. Somente com o 
compartilhamento desses recursos é que conseguimos fechar o círculo virtuoso da criação" (AMIEL, 2014, p. 199).

Nesse sentido, concorda-se com o autor, pois, com o compartilhamento da HQ, o Programa de Monitoria teve uma divulgação mais ampla e rápida, podendo ser difundido em outros campus do IF Goiano e instituições, com a intenção de colaborar para a melhoria no processo de ensino-aprendizagem.

O Produto Educacional foi desenvolvido em formato de $\mathrm{HQ}$ e disponibilizado na forma digital, pois, dentre outras vantagens, um material digital pode ser lido por mais de uma pessoa de uma vez sem custos monetários e pode ser compartilhado de maneira mais rápida entre outras. Assim, desde o processo seletivo para monitores do primeiro semestre de 2019, a HQ digital: "A Importância da Monitoria". Nesse ambiente, a HQ pode ser visualizada e compartilhada por inúmeras pessoas, entre professores, alunos e público externo. Inclusive, encontra-se disponível, na íntegra, no repositório do IF Goiano e no Portal Educapes².

No que se refere a direitos autorais a HQ, utiliza uma licença Creative Commons, do tipo CC BY-NC-ND, que permite que outros façam download da HQ, compartilhem a mesma, porém o crédito deve ser atribuído à autora, não podendo alterá-la ou utilizá-la para fins comerciais.

\subsection{Avaliação e Validação da História em Quadrinhos}

Para realizar a avaliação produto e validar o uso do mesmo, fez-se uma pesquisa por meio de questionário enviado para os e-mails de alunos monitores e não monitores, professores orientadores das disciplinas ofertadas pela monitoria e membros da equipe pedagógica do IF Goiano - Campus Ceres, no período de maio/junho de 2018.

Por meio de um questionário com oito questões fechadas e uma questão aberta, foi realizada a avaliação da aplicabilidade do referido Produto Educacional, e conforme Leite (2018), foi elaborado a partir de cinco componentes: atração, compreensão, envolvimento, aceitação e mudança de ação, buscando avaliar a estética, organização, estilo da escrita, conteúdo, proposta didática e criticidade apresentados no material educativo. Foram obtidas 42 respostas entre os 617 questionários enviados. Entre os respondentes 47,6\% (20) são alunos não monitores, 21,4\% (09) são monitores, 19\% (08) são professores orientadores e 11,9\% (05) são membros da equipe pedagógica.

${ }^{1}$ https://www.ifgoiano.edu.br/home/images/CER/Doc_Ensino/Monitoria/2019/Orientacoes_importancia/Quadrin hos---Clcia.pdf

${ }^{2}$ https://repositorio.ifgoiano.edu.br/handle/prefix/586 e https://educapes.capes.gov.br/handle/capes/553087 
De acordo com as respostas obtidas, na opinião da maioria dos alunos monitores $(55,6 \%)$ e dos alunos que frequentaram as aulas de monitoria $(78,9 \%)$ a HQ estimulou a participação dos mesmos no Programa de Monitoria. Inclusive, dos 20 alunos não monitores que responderam ao questionário, 55\% deles (11 alunos) acessaram, leram a HQ e posteriormente, frequentaram a monitoria no ano de 2019.

Quanto aos professores orientadores, 62,5\% afirmaram que a proposta trazida pela HQ os estimularam a encaminhar alunos com defasagem na aprendizagem em suas disciplinas para participarem das aulas de monitoria, $25 \%$ disseram que não estimulou e $12,5 \%$ não acessaram a HQ.

Quando perguntados alunos, professores e membros da equipe pedagógica se a utilização da HQ pode contribuir para impulsionar alunos monitores, alunos não monitores e professores orientadores a participarem com responsabilidade e dedicação do Programa de Monitoria aplicado no IF Goiano - Campus Ceres, contribuindo, assim para aperfeiçoamento do referido programa, $73,8 \%$ dos respondentes concordaram plenamente que sim, $11,9 \%$ concordaram parcialmente, 9,5\% não concordaram nem discordaram, 2,4\% discordaram parcialmente e $2,4 \%$ não acessaram a HQ.

Quanto à estética e ao aspecto visual, $31 \%$ considerou o produto excelente, $35,7 \%$ muito bom, $19 \%$ bom 7,1\% razoável e 7,1\% não acessaram a HQ. Na opinião do Entrevistado 31 “A história em quadrinhos está em ótimo formato, foi feita com clareza e de entendimento fácil.”. Para o Entrevistado 28 “a ilustração e a história, e a monitoria é bem isso mesmo, quando levada a sério realmente tem aumentado o desempenho dos alunos."

E, no que se refere a clareza de ideias e estilo de escrita, $69 \%$ dos respondentes concordaram plenamente que a HQ facilita a leitura e o entendimento pelos usuários, 21,4\% concordaram parcialmente, $7,1 \%$ não acessaram a HQ e 2,4\% discordaram parcialmente. Para o Entrevistado 06 a HQ tem uma "Escrita bem didática e explica com clareza o programa de monitoria."

Para o membro da equipe pedagógica (Entrevistado 03) a HQ ajudará, com certeza, no aperfeiçoamento do programa, pois esclarece e reforça pontos importantes, que devem ser considerados por todos os professores e alunos.

Após a etapa de avaliação e validação do produto educacional, foi possível perceber que a proposta de trazer inovações, por meio da HQ, que pudessem contribuir para a divulgação, o conhecimento e o aperfeiçoamento do Programa de Monitoria, foi relevante para o IF Goiano - Campus Ceres, pois após ser amplamente divulgado e compartilhado antes do edital referente 
ao ano de 2019, a HQ conseguiu alcançar e estimular alunos e professores a participarem com responsabilidade e empenho do Programa de Monitoria, e assim contribuir para melhoria no processo de ensino-aprendizagem.

\section{CONSIDERAÇÕES FINAIS}

O ensino-aprendizagem é referido como um processo no qual deve haver diálogo, e onde professores e alunos aprendem mutuamente, rompendo os paradigmas tradicionais de repasse unilateral e vertical de conteúdo. Como referenciado, a monitoria destaca-se como propulsora e fortalecedora de tal processo. Dessa forma, por meio dos resultados obtidos e analisados buscou-se aperfeiçoar esse projeto de monitoria com a elaboração de uma HQ abordando o tema. Tal estratégia se mostra eficaz pois, dinamiza a apresentação de temas relevantes, uma vez que as HQs são mais atrativas para o público jovem, sujeitos da pesquisa.

Por ser uma ferramenta ainda pouco explorada de forma reflexiva, sendo a literatura a respeito do papel da monitoria limitada ou de difícil acesso, mesmo em acervos eletrônicos, é de grande relevância a realização de estudos relacionados a ela para mostrar os benefícios que a monitoria pode trazer, a compreensão dos alunos e professores em relação a sua importância e benefícios, bem como para analisar o que pode ser passível de melhora no processo de ensinoaprendizagem, contribuindo assim para a permanência o êxito escolar dos alunos.

Durante a pesquisa a principal dificuldade apontada pelos monitores foi a falta de interesse dos alunos em frequentar as aulas de monitoria, bem como a divulgação insuficiente do programa. Nesse sentido, a pesquisadora desenvolveu seu Produto Educacional, a HQ “A Importância da Monitoria", trazendo os principais informativos sobre o programa e os dados da pesquisa, com a intenção de melhor esclarecer como funciona a monitoria e também influenciar os alunos com defasagem de aprendizagem a frequentarem as aulas.

Percebe-se que os envolvidos no Programa de Monitoria do IF Goiano - Campus Ceres apresentam desempenhos positivos, são mais autônomos e comprometidos em relação à sua aprendizagem. Os dados analisados indicam que, na atividade de monitoria, não só o professor que ensina e produz o pensamento crítico, orientando os monitores, mas também os alunos monitores e não monitores que aprendem juntos, sistematizando diferentes pontos de vista.

Por todo o exposto, verifica-se a importância de discutir novas abordagens e formatos diferenciados e dinâmicos, que facilitem a aplicação e aumentem a eficácia dos Programas de Monitoria, bem como contribuam, ainda mais, com a melhoria do processo de ensinoaprendizagem. Ao término do estudo e do desenvolvimento da HQ, espera-se ainda, o interesse 
de outras instituições de ensino, para o desenvolvimento de programas de monitoria que incentivem a permanência e o sucesso escolar dos alunos.

\section{REFERÊNCIAS}

AMIEL, Tel. Recursos Educacionais Abertos: uma análise a partir do livro didático de história. Revista História Hoje. São Paulo, v.3, n.5, p. 189-205, 2014.

ANASTASIOU, Léa das Graças Camargo; ALVES, Leonir Pessate. Estratégias de ensinagem. In: ANASTASIOU, Léa das Graças Camargo; ALVES, Leonir Pessate (Org.). Processos de ensinagem na universidade: pressupostos para as estratégias de trabalho em aula. Joinville-SC: UNIVILLE, 2006. p. 67-100.

BRASIL. Capes. Documento de Área - Ensino. 2013 Disponível em:

https://capes.gov.br/images/stories/download/avaliacaotrienal/Docs_de_area/Ensino_doc_area e_comiss\%C3\%A3o_block.pdf . Acesso em: 24 mai. 2019.

BRASIL. Plano de Desenvolvimento Institucional (PDI) 2019-2023. Goiânia, GO: 2018. Instituto Federal Goiano. Disponível em:

https://suap.ifgoiano.edu.br/media/documentos/arquivos/39__PDI_2019-2023 _ _revisado_18-03-2019.pdf. Acesso: em 24 mai. 2019.

BRASIL. Resolução CNS n 466, de 12 de dezembro de 2012. Ministério da Saúde.

Conselho Nacional de Saúde. Brasília/DF: 2012. Disponível em:

http://bvsms.saude.gov.br/bvs/saudelegis/cns/2013/res0466_12_12_2012.html. Acesso em: 23 mai. 2018.

BRASIL. Resolução CNS no 510, de 07 de abril de 2016. Ministério da Saúde. Conselho Nacional de Saúde. Brasília/DF: 2016. Disponível em:

http://bvsms.saude.gov.br/bvs/saudelegis/cns/2016/res0510_07_04_2016.html. Acesso em: 25 jun. 2019.

CAVALHEIRO, Patrícia da Silva. Monitoria como Estratégia Pedagógica para o Ensino de Ciências no Nível Fundamental. Dissertação (Mestrado em Educação em Ciências) Universidade Federal do Rio Grande do Sul, Porto Alegre, 2008.

CIAVATTA, Maria. A formação integrada: a escola e o trabalho como lugares de memória e de identidade. In: FRIGOTTO, Gaudêncio; CIAVATTA, Maria; RAMOS, Marise. (Orgs.). Ensino Médio Integrado: concepção e contradições. 3. ed. São Paulo: Cortez, 2012. p. 83106.

FRIGOTTO, Gaudêncio; CIAVATTA, Maria; RAMOS, Marise. A gênese do Decreto n. ${ }^{\circ}$ 5.154/2004: um debate no contex to controverso da democracia restrita. In: FRIGOTTO, Gaudêncio; CIAVATTA, Maria; RAMOS, Marise (Org.). Ensino Médio Integrado: concepção e contradições. 3. ed. São Paulo: Cortez, 2012. p. 21-56.

FRISON, Lourdes Maria Bragagnolo; MORAES, Márcia Amaral Corrêa de. As práticas de monitoria como possibilitadoras dos processos de autorregulação das aprendizagens discentes. Revista Poíesis Pedagógica, Goiás: UFG, v. 8, n. 2, p. 144-158, ago. / dez. 2010. 
GRAMSCI, Antônio. Os intelectuais e a organização da cultura. Rio de Janeiro: Civilização Brasileira, 1995.

GIL, Antônio Carlos. Como elaborar projetos de pesquisa. 5. ed. São Paulo: Atlas, 2010.

HAAG, Guadalupe Scarparo; KOLLING, Vanessa; SILVA, Elisete; MELO, Silvana Cláudia Bastos; PINHEIRO, Monalisa. Contribuições da monitoria no processo ensino-aprendizagem em enfermagem. Revista Brasileira de Enfermagem. Brasília, p. 215-220, mar-abr, 2008. Disponível em: http://www.scielo.br/pdf/reben/v61n2/a11v61n2.pdf. Acesso em: 10 out. 2017.

JESUS, Daniele Maria Oliveira de; MANCEBO, Rafael Cuba; PINTO, Fernando Igor Pinho; BARROS, Giovanni Victor Evangelista. Programas de monitorias: um estudo de caso em uma IFES. Revista Pensamento Contemporâneo em Administração. Rio de Janeiro, v. 6, n. 4, p. 61-68, out./dez. 2012. Disponível em: http://periodicos.uff.br/pca/article/view/11109. Acesso em: 17 out. 2017.

KAPLÚN, Gabriel. Material Educativo: a experiência de aprendizado. Comunicação \& Educação. São Paulo, v. 27, p. 46-60, mai./ago. 2003.

KUENZER, Acácia Zeneida (Org.). Ensino Médio: construindo uma proposta para os que vivem do trabalho. 3. ed. São Paulo: Cortez, 2002.

LEITE, Priscila de Souza Chisté. Produtos educacionais em mestrados profissionais na área de ensino: uma proposta de avaliação coletiva de materiais educativos. In: Congresso IberoAmericano em Investigação Qualitativa, 7, 2018, Fortaleza. Anais[...] Fortaleza: UNIFOR, 2018. Disponível em:

https://proceedings.ciaiq.org/index.php/ciaiq2018/article/view/1656/1609. Acesso em: $12 \mathrm{dez}$. 2018.

MENDONÇA, Márcia Rodrigues de Souza. Um gênero quadro a quadro: a história em quadrinhos. In: DIONÍSIO, Angela Paiva; MACHADO, Anna Rachel; BEZERRA, Maria Auxiliadora (Org.). Gêneros Textuais e Ensino. 5. ed. Rio de Janeiro: Lucerna, 2007.

MOREIRA, Marco Antônio. O mestrado (profissional) em ensino. Revista Brasileira de Pós-Graduação. Brasília, n. 1, p. 131-142, 2004.

OLIVEIRA, Vânia Lúcia Bezerra. et al. Modelo explicativo popular e profissional das mensagens de cartazes utilizados nas campanhas de saúde. Texto Contexto Enfermagem. Florianópolis, v. 16 n. 2, p. 287-293, abr./jun. 2007. Disponível em:

http://www.scielo.br/scielo.php?pid=S010407072007000200011\&script=sci_abstract\&tlng=pt . Acesso em: 23 jul. 2019.

PACHECO, Eliezer (Org.). Institutos Federais: uma revolução na educação profissional e tecnológica. São Paulo: Editora Moderna, 2011. p. 05-12.

RAMOS, Marise Nogueira. Concepção do Ensino médio integrado. Disponível em: https://tecnicadmiwj.files.wordpress.com/2008/09/texto-concepcao-do-ensino-mediointegrado-marise-ramos1.pdf. Acesso em: 14 out. 2017. 
REBOLHO, Marilia Christina Tenorio; CASAROTTO, Raquel Aparecida; JOÃO, Silvia Maria Amado. Estratégias para ensino de hábitos posturais em crianças: história em quadrinhos versus experiência prática. Fisioterapia e Pesquisa. São Paulo, v. 16, n. 1, p. 4651, jan./mar. 2009. Disponível em:

https://www.revistas.usp.br/fpusp/article/download/12124/13901/0. Acesso em: 23 jul. 2019.

SOUSA, Maria do Carmo. Produtos educacionais de Matemática elaborados por professores da Educação Básica no âmbito do NIPEM. Disponível em:

http://www.enrede.ufscar.br/participantes_arquivos/E3_Sousa_TA.pdf. Acesso em: 23 mai. 2019.

VERGUEIRO, Valdomiro. Como usar as histórias em quadrinhos na sala de aula. São Paulo: Contexto, 2004.

Recebido em: 23 de julho de 2019.

Aprovado em: 30 de março de 2020. 